would like to acknowledge with gratitude the help, collaboration and inspiration which we received from the late Professor Ben Platt and to pay tribute to the influence he had on knowledge of nutrition in general and of nutritional anaemias in particular.

\title{
REFERENCES
}

Allen, R. F. \& Dean, R. F. A. (1965). Trans. R. Soc. trop. Med. Hyg. 59, 326.

Joske, R. A., McAlister, J. M. \& Prankerd, T. A. J. (I956). Clin. Sci. I5, 5 Ir.

McKenzie, D., Friedman, R., Katz, S. \& Lankowsky, P. (1967). S. Afr. med. \%. 4r, ro44.

Platt, B. S., Heard, C. R. C. \& Stewart, R. J. C. (1964). In Mammalian Protein Metabolism. Vol. 2, p. 446 [H. N. Munro and J. B. Allison, editors]. New York and London: Academic Press.

Platt, B. S. \& Stewart, R. J. C. (1968). Devl. Med. Child Neurol. ro, 3.

Reismann, K. R. ( $1964 a)$. Blood 23, 137.

Reismann, K. R. (1964b). Blood 23, I 153 .

Sood, S. K., Deo, M. G. \& Ramalingaswami, V. (1965). Blood 26, 42 I.

Trowell, II. C. (1937). Archs Dis. Childh. 12, 193.

Wharton, B. A. (1968). Calorie Deficiencies and Protein Deficiencies p. 147. London: J. and A. Churchill Ltd.

Woodruff, A. W. (1951). Br. med. F. 2, 1415.

Woodruff, A. W. (1955). Br. med. $尹$. I, 1297.

Woodruff, A. W. (1959). Proc. int. Congr. trop. Med. Malar. 6, 499.

Woodruff, A. W., Shafei, A. Z., Awwad, H. K., Pettitt, L. E. \& Abaza, H. H. (1966). Trans. R. Soc. trop. Med. Hyg. 6o, 343.

\section{Host-parasite relations: nutrition and genetics in filariasis}

\author{
W. E. Kershaw, D. M. Storey and Phyllis D. Wells, \\ Department of Biology, University of Salford
}

The term 'host-parasite relations' is misleading. Conventionally, parasites are considered as being related to hosts in the way that a pathogenic bacterium produces a disease. Parasitism, however, is more than this. It is a biological system which enables creatures to live together. The system enables each to adapt itself to some extent to the other but again this system is more than merely host and parasite. Many parasites are transmitted by vectors, sometimes by several. The parasite, the host and the vector all have their own environments, which are mostly separate, but must be shared on the instant that the parasite is transmitted. One should therefore consider host-parasite-vector-environment combinations; each of the components has evolved within the evolution of the whole combination.

Parasites are dependent for transmission on the accident of the environment and on accidents of the habits of their hosts. The accident of environment may allow a parasite to be transmitted to one host and give no opportunity of transmission to another, thus providing an example of specificity limited by environmental accident. An example is Loa loa, a filarial parasite living in the connective tissue of man and certain monkeys in the rain forest in West and Central Africa. It produces the transient swellings known as Calabar swellings, and an alarming incident when 
the adult worms, which migrate in the connective tissues, cross the connective tissue under the conjunctiva. This infection was responsible for much apprehension and led to sufficient difficulties in the recruitment of Europeans to the Colonial Service, and to commercial undertakings in Eastern Nigeria and the Cameroons for a research organization to be set up in 1949. After some 16 years of work, it is possible now to understand the main pattern of the epidemiology of this infection. In the human infection, the first-stage larvae, the microfilariae, occur in the peripheral circulation during the day only and the infection is transmitted from man to man by two day-biting species of Chrysops which bite on the forest floor where man normally moves. In the monkey infection, the microfilariae occur in the peripheral blood during the night and are transmitted from monkey to monkey by three other species of Chrysops which bite during the night in the forest canopy where the monkeys live during the night. All these five species of Chrysops will support the development of, and can act as vectors experimentally of, both kinds of infection; human Loa loa can be transmitted experimentally quite readily to monkeys. My own belief is that, if the appropriate experiments could be done, it could be shown that monkey infection could be transmitted as readily to man. The separation of these two infections, in natural circumstances, the one to monkey and the other to man, has become possible through a change in habit of two species of Chrysops. It is likely that Chrysops evolved in the savannah regions and five species invaded the forest, which could be regarded as the savannah raised on stilts. Three of them, which bite after dusk, continued to live in the forest canopy and feed on monkeys. Two of them developed the ability to migrate to the forest floor and feed on animals, including man. All the flies breed in the same situation on the forest floor. The apparent specificity of these two infections to two different hosts, man and monkey, is due to the accident of the environment manifest in the difference in behaviour of the vector.

In sleeping sicknesss in man and in trypanosomiasis in animals, host-parasite specificity has long been recognized and, during the past to years, much fundamental work on the chemistry and serology has made the relation between parasite and host better understood. Those who wish to pursue this subject should consult the book The African Trypanosomiases (Mulligan, 1970).

Trypanosoma brucei, one of the parasites occurring in wild game and completely tolerated by them, produces disease when transmitted to domestic animals, and a similar parasite, $T$. rhodesiense, causes infection in man in East Africa. So similar are these two parasites morphologically and, until recently, in most other ways, that $T$. rhodesiense could only be differentiated from T. brucei when an inoculation of it into a human volunteer produced the infection. Here is an example of host specificity used as a biological test to identify the organism. Similarly, T. vivax, an animal trypanosome occurring in sheep, cannot be transmitted to rats unless its injection is accompanied by large amounts of sheep serum. After many passages, with decreasing quantities of serum, it is possible to produce an organism, obviously changed, which will support itself on passage in rats without the supplement of serum.

Cotton-rats are refractory to infection with some trypanosomes and the mecha- 
nism responsible for this refractoriness is now being investigated by Dr R. J. Terry at Brunel University with the encouragement of the Trypanosomiasis Advisory Panel of the Ministry of Overseas Development.

These examples from trypanosomiasis show an 'all or none' mechanism in which a host refuses a parasite although it is given the optimal chance of transmission by direct implantation into its tissues.

Two examples of infections have been given, one helminthic and one protozoal. Protozoal and helminthic infections differ in their biological make-up. In protozoal infections, in theory, one trypanosome can lead to infection of the host and can, by asexual multiplication within the host, produce saturation. Theoretically, one malarial sporozoite can start the life-cycle and by asexual multiplication fill the host. In practice, there may be for other reasons a minimal dose of infective forms to establish infection, but the subsequent saturation by asexual multiplication is still true. Like pregnancy, one has malaria or one has not; one has sleeping sickness or one has not; and in first infections with either, one has it in abundance. In vectorborne helminthic infections, there is no asexual cycle corresponding to the explosive phase in the protozoa. One infective form put in by the vector can produce only one adult, and if a number of forms are put in, the number of adults produced cannot be greater than those put in and may be less. The only way, therefore, to establish an intense infection is for large numbers of infective forms to be put it. And, in general, the numbers of the next generation, again with the hall-marks of sex in them, are limited by the numbers originally put in as infective forms. The host may have then a light infection with one or other form of, for example, filariasis, which many of us have had, or a moderate infection or an intense infection, according to exposure. Because of this, it is possible to measure the intensity of infection and there is a quantitative means of establishing host-parasite relations.

Cotton-rat filariasis is transmitted by the tropical rat mite. After some 25 years of work, it is now a precise, easily manipulated and dependable infection in the laboratory. In this infection, the adult worms live in the pleural cavity and the microfilariae appear in the peripheral blood. The exposure of the animal to infection can be estimated by counting the populations of mites to which the animal is exposed and the numbers which feed; and by measuring the infection rates and intensities in the population of the mites before and after they are fed on the animal. From this information, an estimate can be made of the exposure to infection. (The mathematical details of the several methods of arriving at this estimate are omitted from this paper.) This estimate of exposure can be compared with the number of worms which subsequently develop in the pleural cavities of the animal (Kershaw, 1962). We can therefore measure host-parasite relations by the susceptibility of the host to the infection, that is the number of worms which develop from known exposure, by rate of growth of the worms in the host, by its associated pattern of infection (i.e. whether the increase of microfilariae in the blood conforms to the normal pattern or not) and by the effect of the parasite on the host as measured by rate of growth of the host and its mortality and any other vital functions.

Twenty-five years ago, this infection could only be transmitted with ease through 
cotton-rats; the white rats which were then available at the Liverpool School of Tropical Medicine would not support development, for few worms were produced and they lived for a shorter time than those in the cotton-rats. Hitherto, we had thought that only cotton-rats were susceptible to cotton-fat filariasis and since cotton-rats were considered difficult to breed, particularly in the large numbers needed for the screening of drugs, attempts had been made to transmit the infection to other easily reared laboratory animals such as white rats.

Nine years ago, at the Malarial Institute of India, it was found that a strain of white rats, thereafter known as Delhi white rats, could be infected with cotton-rat filariasis; the adult worms persisted long enough for microfilariae to be present in the circulation for a time sufficient to enable the animals to be used for the screening of drugs against filariasis. In other words, the Delhi white rat was behaving in a way similar to the original cotton-rat. My colleagues Dr A. Siddiqui, Dr J. N. Hodgson and $I$ at Liverpool then examined some twenty or thirty strains of different white rats and mice for their ability to support the development of the parasite and we found that the hooded white rat, the multimammate mice and, surprisingly enough, the progeny of the original strain of Liverpool white rats were able to support the development of the infection; the others were refractory to the infection (Siddiqui, 1965; Hodgson, 1964).

At this time, the late Professor B. S. Platt was concerned with the notion of protein-calorie deficient diets. My colleagues and I at the Liverpool School of Tropical Medicine asked his co-operation in experiments to see whether nutrition had any effect on host-parasite relations (which in its clear-cut form is usually referred to as host-parasite specificity), since we were now able to measure these relations in filariasis with confidence. Using the number of adult worms produced from an assessed exposure and the length of the worms as a measure of host-parasite relations, my colleague, Dr Hodgson, and I then investigated the susceptibility of cotton-rats and Liverpool white rats in different nutritional states, by feeding unrestricted diets containing varying amounts of protein (Hodgson, 1967). We chose these two strains of rats merely because we had maintained them in the Liverpool School of Tropical Medicine for some 20 years as experimental animals. In retrospect it now seems desirable that we should have tried the effect of changed nutrition on the infection in strains of rats which were not susceptible to infection with filariasis. This omission we hope now to remedy. (It will be appreciated that these experiments are extremely time-consuming.)

The susceptibility of cotton-rats to filariasis was not altered by feeding them on unrestricted and unmeasured diets of $5 \%$ protein and $10 \%$ protein with fat and carbohydrate. In Liverpool white rats fed on the lower-protein diet, fewer and smaller worms were produced than in animals fed on the higher-protein diet. There was, therefore, a difference in host-parasite relations produced by a difference in diet in one susceptible animal, the Liverpool white rat, and not in another, the cotton-rat.

May I make a short incursion here concerning vitamin A? In 1966 , I was appointed to the Chair of Biology at the University of Salford and there, Dr P. D. Wells and 
Mr J. Rogerson (Rogerson, 1967 ) had been working on the effect of vitamin A on the susceptibility of rats to infection with Nippostrongylus brasiliensis, a nematode which lives in the gut. Mr D. M. Storey and I then worked on the effect of vitamin A deficiency on host-parasite relations in filariasis of the cotton-rat (Storey, 1967) in which it had been shown at Liverpool that no change in susceptibility was produced by varying the protein content of an unrestricted diet. Mr Storey showed that the cotton rats which were fed on a diet normal in every respect except for its vitamin $A$ content harboured more and larger worms when vitamin $A$ was deficient than those who were fed on a normal diet with a vitamin A supplement.

After this temporary deviation to vitamin $A$, we returned to experiments on measured diets containing different amounts of protein fed to cotton-rats infected with filariasis. We have found that a diet of moderately low-protein content affects the rate of growth of infected rats and produces increased mortality. A diet very low in protein produces even more retardation of growth and further enhances mortality. Furthermore, the host-parasite relation in diets moderately low in protein is altered in that, although the number of worms established on known exposure is unaltered, the growth of the worms is retarded both in their length and in the development of their genital apparatus. In diets very low in protein these two effects are more marked. We do not know yet whether this represents a slowed rate of growth which would result in final arrest of growth or whether, if given longer, the worms might reach maturity.

Infection with filariasis in cotton-rats in a state of undernutrition increases the mortality when compared with those not infected and also retards even further the rate of growth of the rats. A few experiments have been done with Liverpool white rats and with hooded rats; the results are similar to those found with cottonrats but the effect of a low-protein diet on the worms is more marked than in cottonrats.

In all these experiments, in which the amount of protein has been varied, the amount of fat has remained constant but the amount of carbohydrate has been altered so as to produce diets of the same calorific value. We propose to carry out experiments to see whether the effect of a low-protein and low-carbohydrate diet is different from that of a low-protein and high-carbohydrate diet, and we are now investigating the serological reactions of rats on different diets in response to filarial infection.

In summary then, different genetic strains of rats on normal diets respond differently to infection with cotton-rat filariasis. In one of them, the present generation of Liverpool white rats, changes in host-parasite relations are much more easily induced by low-protein diets than in another, the cotton-rat, which is the normal host for the parasite. The effect of nutrition on host-parasite relations is dependent upon the genetic make-up of the host.

We have also shown that in a well-adapted host, the cotton-rat, low-protein diets influence host-parasite relations not by changing the number of worms established in an infection but by altering the development of the parasite. Further, infection of the cotton-rat on a low-protein diet enhances the adverse effect of that diet. 


\section{REFERENCES}

Hodgson, J. N. (I964). Cotton rat filariasis in the white rat (Liverpool strain). MSc Thesis, University of Liverpool.

Hodgson, J. N. (1967). The effect of nutrition on host-parasite relations in cotton rat filariasis. $\mathrm{PhD}$ Thesis, University of Liverpool.

Kershaw, W. E. (1962). Bull. Soc. Path. exot. no. 4, p. 476.

Mulligan, H. W. (editor). (I97o). The African Trypanosomiases Ist ed, London: George Allen and Unwin. (In the Press.)

Rogerson, J. (1967). Intestinal cellular changes in vitamin A-deficient rats infected with Nippostrongylus brasiliensis. MSc Thesis, University of Salford.

Siddiqui, M. A. (1965). The quantitative transmission of cotton rat filariasis to laboratory animals, including the effect of irradiation. PhD Thesis, University of Liverpool.

Storey, D. M. (1967). The effect of vitamin A deficiency on the host-parasite relationships in cotton rat filariasis. MSc Thesis, University of Salford.

\section{Social and nutritional influences on morbidity: a community study of young children in Lagos}

By J. N. RE**, Institute of Child Health, University of Ibadan and University of Lagos Medical School

In 1965 the WHO Expert Committee on Nutrition and Infection suggested that: 'In developing countries where for many reasons vital and statistical data are incomplete, valuable information can be obtained by long term longitudinal studies in selected representative population groups.' (WHO, r 965.) The study here described is in line with this suggestion though its length ( $1 \cdot 5^{-2}$ years) was relatively short. Longitudinal observations on nutrition and morbidity were recorded on representative Nigerian children under 5 years of age in the urban setting of Lagos. The survey was undertaken in order to measure the medical care needs of this age group which contributed more than half of all registered deaths at a time of expansion and change in the health services of Lagos.

\section{Selection of subjects}

Children under 5 years of age were selected from five districts of Lagos (Rea, I969) and divided into three socio-economic groups.

Group I (ninety-six children) came from a 'control' group of families of professional or executive status living in a new freehold housing development in the suburb of Suru Lere. Housing was good, though overcrowded by British standards.

Group 2 ( $55^{\circ}$ children) came from a recently built (1957), though overcrowded, low-cost housing estate in Suru Lere and from the older suburb of Yaba.

Group 3 ( 165 children) came from the very overcrowded traditional district of Isale Eko on Lagos Island and from the peripheral slum area of Mushin.

Most families, even in groups 2 and 3 , had access to a piped water supply of good quality. Group I families were volunteers; groups 2 and 3 were randomly selected by

*Present address: James Wigg Centre, I I2-II4 Kentish Town Road, London, NWI.

$29(2) 4$ 